Article

\title{
Did Haze Pollution Harm the Quality of Economic Development?-An Empirical Study Based on China's PM2.5 Concentrations
}

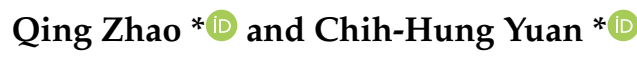 \\ School of Economics and Commerce, University of Electronic Science and Technology of China, \\ Zhongshan Institute, Zhongshan 528400, China \\ * Correspondence: zhaoguoqing1977@163.com (Q.Z.); ialexyuan@gmail.com (C.-H.Y.)
}

Received: 12 January 2020; Accepted: 18 February 2020; Published: 21 February 2020

\begin{abstract}
Based on the PM2.5 haze data of China's provinces between 2004-2016, this paper systematically explores the impact of haze pollution on the quality of China's economic development, as well as its transmission mechanisms. This is achieved by measuring the quality of economic development with total factor productivity. Furthermore, this paper innovatively uses precipitation as an instrumental variable for mitigating the endogeneity of the haze pollution variable, by which the impact of haze pollution on the quality of China's economic development is estimated within the framework of two-stage least squares. It is found that: the haze pollution has degraded the quality of China's economic development significantly; the labor supply loss, counter urbanization and human capital disruption are the three major transmission channels through which haze pollution affects the quality of China's economic development; strengthening government's environmental management is effective in mitigating the adverse impact of haze pollution on the economic development quality; and that China's unique fiscal decentralization system has exacerbated the negative economic effect of haze pollution. The policy implications of this paper are as follows: Improvement of economic development quality is a prerequisite for the transition of economic development mode; and the governmental management of haze is conducive to enhancing the quality of atmospheric environment and economic development, and to promoting the high-quality development of the Chinese economy.
\end{abstract}

Keywords: haze pollution; economic development quality; environmental management; PM2.5 concentration

\section{Introduction}

Since the reform and opening up policies were implemented, China's economy has grown continuously at a high pace for many years, with its economic aggregate leaping up to become the world's second largest. In terms of per capita income, China has also been ranked as a middle- and high-income economy. Nevertheless, the extensive rapid growth over the years and the traditional idea of GDP predominance have also led to a series of problems in China's economic growth, such as input factor wastage, low economic efficiency and severe environmental pollution. In particular, the quality of atmospheric environment has declined, and the occurrence of haze has become frequent. In 2013, the "haze from all sides" spread to more than 100 large- and medium-sized cities in 25 provinces, which has threatened people's daily lives severely. In the 2018 Global Environmental Performance Index rankings, China ranked 120th among 180 countries and regions. What is worse, the air quality indicator for China ranked fourth from the bottom. In the meantime, China's economic growth rate has fallen to around $6 \%$ since 2012, signaling a transition towards a stage of high-quality development. Consequently, the conflicts between economic growth and environment have become ever more complicated and fiercer. The severe haze pollution is the red flag raised by nature towards the extensive growth mode 
that has been utilized. The only way of improving the environment and enhancing the quality of economic development is to thoroughly manage various forms of environmental pollution like haze. Its significance not only lies in the haze itself, but is also linked to the fundamental transformation of the economic development mode and sustainable high-quality development in China. This paper attempts to answer the following key questions that have not yet been well answered: Did China's aggravating haze pollution harm the quality of its economic development, and what is the mechanism behind it? Can a win-win be achieved for environmental and economic dividends? Beyond doubt, the answers to these questions are of profound theoretical and practical significance for China to achieve the sustainable development path of 'valuing both the economy and the environment'.

Concerning the relationship between economic development and environmental pollution, the majority of extant literatures have focused on the unidirectional relationship of how economic development affects environmental pollution by using the Environmental Kuznets Curve (EKC) model as the main framework, while the reverse impact of environmental pollution on economic development has scarcely been studied [1-5]. As a matter of fact, economic growth and the environment constitute a large interactive system, so it is possible that the environmental degradation affects economic growth as well. Lopez [6] regarded the environment as an important factor for production input. According to the Report on Losses from Environmental Pollution in China released by the World Bank in 2007, the losses arising from air and water pollution in China were equivalent to $5.8 \%$ of its actual GDP that year. An empirical study covering 59 countries by Despina Giannadakia et al. [7] revealed that cutting agricultural emissions by 50\% each year could reduce 200,000 deaths, especially in Europe, Russia, Turkey, the United States, Canada and China. This was accompanied by billions of dollars in economic benefits. The research on the economic consequences of environmental pollution has concentrated on the impact of pollution on residents' health [8,9]. In contrast, there are few literature articles on the impact of environmental pollution on economic development, and those on the impact of haze pollution on economic development are even more scarce [10]. According to Zhang et al. [11], haze pollution produces a tremendous negative impact on stock returns through the emotional channels of investors. A static model-based estimation by Jibo et al. [12] showed that the indirect economic losses caused by haze pollution in Beijing to the transportation sector amounted up to 23.7 million yuan in 2013. In light of this, the present paper carries out a systematic empirical investigation around the impact of haze pollution on the economic development quality and its relevant mechanism based on the provincial panel data of China between 2004-2016. This is achieved by taking the total factor productivity as a measure of economic development quality, and by characterizing the degree of haze pollution with satellite-monitored PM2.5 concentrations. To be specific, the marginal contribution of this paper is reflected in the following three aspects: First of all, unlike most research which examined the impact of economic development on haze pollution, this paper systematically studies the impact of haze pollution on China's economic development, and reveals the importance of environmental surveillance and management, thereby offering an empirical evidence for local governments who seek a win-win between environmental protection and economic growth. Secondly, a major challenge in exploring the impact of haze pollution on China's economic development is endogeneity. In rainy and snowy weathers, haze pollution tends to decline prominently. Meanwhile, both the rainfall and snowfall are determined by meteorological system and are well exogenous. Accordingly, this paper innovatively uses the annual precipitation converted by rain and snow as an instrumental variable of haze pollution, in order to mitigate the potential endogeneity problem. Thirdly, despite the discussion on the extent of harm caused by air pollution to the economic development, Yu Hao [10] failed to analyze the specific path via which the haze pollution harmed the quality of economic development. After a review of extant literature, this paper puts forward that the air pollution affects economic development mainly through the "labor supply loss effect", "counter urbanization effect" and "human capital disruption effect", thereby enriching the theoretical literature on the economic consequences of environmental pollution. 
The reminder of this paper is organized as follows: Section 2 reviews the literature and proposes research hypotheses; Section 3 presents the econometric models and relevant variables; Section 4 analyzes the empirical results; and Section 5 summarizes research conclusions and policy recommendations.

\section{Literature Review and Hypothesis Formulation}

Unregulated pollutant emissions affect the economic growth in two ways. One way is to give play to the natural environment's role of absorbing and depositing wastes. Where other input factors are given, the economic establishments can increase their output level through depletion of the natural environment, thereby bringing about an overall positive impact on economic growth. The problem is that although individual economic establishments can improve their output by increasing pollutant emissions, the ongoing accumulation of emissions will reduce the environmental carrying capacity of the entire society continuously, as well as the quality of the natural environment. This will eventually bring about negative externalities to the output or quality of various economic establishments, and even the macroeconomy. The ultimate impact of such unregulated pollutant emissions on economic development depends on the relative changes between positive and negative effects. Specific to haze pollution, its negative impact on economic development has been discussed in the extant literature covering at least three aspects. Firstly, air pollution harms the health of individuals and lowers the supply of labor. Secondly, haze pollution reduces the attractiveness of cities significantly, thereby limiting the effective exertion of the urban agglomeration effect and ultimately slowing down economic development [13]. Thirdly, haze pollution damages the accumulation of human capital, which is one of the foremost drivers of economic development. Thus, clearly, haze pollution can also suppress economic development by slowing down human capital accumulation [14]. In view of this, this paper analyzes the specific transmission mechanisms whereby haze pollution affects China's economic development quality from the perspectives of labor supply, urbanization and human capital.

\subsection{Air Pollution and Loss of Labor Supply}

Air pollution has been proven by extensive pathological and sociological studies to have a variety of negative effects on human health, such as shortening average life expectancy [15], increasing morbidities of respiratory diseases and lung cancer [16] as well as causing more premature deaths amongst the working population [17-19]. Therefore, air pollution may reduce the supply of labor by harming human health. As early as in 1983, Bart conducted a quantitative research on relevant U.S. data by employing the ordinary least squares model. He claimed that for every $10 \%$ increase in total suspended particulates in the air, the number of lost labor days increased by $4.4 \%$. Utilizing the same data by controlling the inter-city differences, Hausman et al. [20] reported that the number of lost labor days increased by 0.1 for each standard deviation of particulate pollutants. Based on the observation of the external pollution variation resulting from the shutdown of a large Mexican oil refinery, Hanna and Oliva [21] calculated the $\mathrm{SO}_{2}$ levels as the pollutant. They concluded that the closure of the refinery has led to a pollution reduction in the surrounding communities by $19.7 \%$, as well as an increase of weekly working time by $1.3 \mathrm{~h}(3.5 \%)$. Bosi [22] studied the short- and long-term effects of pollution in the Ramsey model. They determined the sufficient conditions for the existence and uniqueness of long-term equilibrium based on an argument that the "pollution and labor supply are inseparable in household preferences". Furthermore, through the flip branch research model, they proved that a tremendous negative impact of pollution on labor supply would cause macroeconomic fluctuations, thereby providing a theoretical basis for the eco-friendly fiscal policies. Carson et al. [23] found from a survey of 4259 households made by the Bangladesh Bureau of Statistics in 2000 that in rural areas with severe arsenic exposure, the labor supply level was 7.9\% lower than that in non-exposed areas. Aside from damaging the health of laborers themselves, the long-term exposure to severe air pollution may also compel the adult laborers to spend more time caring for infected children and elders, thereby resulting in an increased absenteeism and shortened working hours. Kim et al. [24] studied the 
medium- and long-term effects of air pollution on labor supply based on a natural experiment of the 1997 Indonesian forest fires. They found that the exposure to air pollution shortened the working hours of laborers, and that the parents with children were more prone to working hour reductions during severe pollution incidents. In addition, the medium- and long-term effects of pollution were more drastic. Hence, haze pollution may reduce the labor supply in heavily polluted areas, thereby endangering the quality of economic development.

\subsection{Air Pollution and Counter Urbanization}

Tending to benefits and avoiding harms are an instinctual stress response of living organisms. During the 1960s and 1970s, severe haze pollution broke out in the Los Angeles area of California, United States. After the 1970s, the state government decided to implement a haze removal plan, which resulted in a significant increase in population with the reduction of haze, especially in the underprivileged districts. On the one hand, the settlement of haze problem enhanced people's residential willingness remarkably, thereby lowering the population outflow rate. On the other hand, the demand for labor increased, and the number of immigrants grew accordingly, so that the area turned from a population outflow region into an inflow region. This implies that people can avoid harsh living environments through migration. With continuous intensification of urban environmental pollution, some susceptible people in poor physical conditions have chosen to leave the heavily polluted cities, since they were worried about the pollution-induced health damage. Chen et al. [25] examined the migration effect of air pollution from an emigration place perspective. Based on the China census sampling data, they calculated the population emigration rate at the county level, who found that the air pollution promoted the outflow of population. A research based on city-level data by Qin and Zhu [26] confirmed that the frequency of people searching for immigration via the Internet was elevated during periods of exacerbated air pollution. Unlike the foregoing studies which were from the perspective of emigration to another place, Kahn [27] investigated the impact of air quality on population growth by utilizing the California county-level sample data. They found that the improvement of air quality led to a substantial regional inflow of immigrants, as well as a rapid growth of population. Urbanization, as a major force driving the improvement of economic quality, has effectively reduced the surplus rural labor, thereby providing sufficient labor for the development of manufacturing and service industries while enhancing the efficiency of agricultural production, which has ultimately driven the overall economy forward. Haze pollution, however, has lowered the attractiveness of cities. As a result, the migrants' willingness to stay declined, which further limited the effect of increasing returns to urban scale and the agglomeration effect, ultimately slowing down economic development [13].

\subsection{Air Pollution and Human Capital Disruption}

Air pollution increases the probability of labor migration, and when making migration decisions, highly qualified laborers are more sensitive to air pollution. This is attributable to the wider choices and job alternatives offered to these laborers. So they can bear the economic consequences of leaving the workplace temporarily or reducing working hours when faced with the dangers of air pollution. In contrast, low-quality laborers have a lower human capital reserve, which reduces the flexibility of their work choices. Therefore, they will not easily quit existing jobs even in the face of severe air pollution. Cole et al. [14] found that the high-skilled employees had a stronger ability to avoid air pollution, who were capable of bearing the corresponding switching costs, and were more inclined to work in the low polluted industries or regions. As a result, highly polluted cities can hardly retain high-skilled employees. In fact, some companies already tried to prevent the outflow of employees by increasing their medical insurance expenses and paying additional "welfare subsidies" for air pollution [28]. Additionally, air pollution damages the health of individuals, which traps them into negative emotions to weaken their creativity and work motivation, thereby reducing the output capacity of human capital. Targeting the Chinese manufacturing firms between 1998-2007, Fu et al. [29] 
estimated the impact of air pollution on the corporate output per capita by using the IV method. Furthermore, they explained the mechanism whereby air pollution suppressed the corporate output per capita from the perspective of internal production relationships. Human capital is one of foremost factors promoting the improvement of economic quality, especially with the consideration that the economic development has fully entered the era of the knowledge economy. Haze pollution may be notably detrimental to the accumulation of local human capital.

Based on the above analyses, this paper proposes that the haze pollution hinders the sustainable development of economy through the "labor supply loss effect", "counter urbanization effect" and "human capital disruption effect".

\section{Model Building and Indicator Selection}

To investigate the impact of haze pollution on the quality of China's economic development, this paper builds the following benchmark regression model:

$$
\mathrm{TFP}_{\mathrm{it}}=\mathrm{a}_{0}+\mathrm{a}_{1} \text { PM2.5 } 5_{\mathrm{it}}+\mathrm{a}_{2} \text { Density }_{\mathrm{it}}+\mathrm{a}_{3} \text { FDI }_{\mathrm{it}}+\mathrm{a}_{4} \text { Innov }_{\mathrm{it}}+\mathrm{a}_{5} \text { Indus }_{\mathrm{it}}+\gamma_{\mathrm{i}}+\mu_{\mathrm{t}}+\varepsilon_{\mathrm{it}} .
$$

\subsection{Dependent Variable}

Where TFP stands for total factor productivity of economy, and is used for measuring the quality of economic growth. The core of economic growth quality is efficiency. The economic total factor productivity has been recognized universally as a proxy variable. Organizations like the World Bank and the OECD have also listed total factor productivity as a crucial referential indicator for studying the quality of China's economic growth. Based on the DEA-Malmquist index model, we calculated the economic total factor productivities (TFPs) of various provinces over the studied years using DEAP 2.1. In this paper, the capital (unit: 100 million yuan), labor (unit: 10,000 people) and total energy consumption (unit: 10,000 tons of standard coal) were selected as the input variables. Meanwhile, the regional total output value (unit: 100 million yuan) was chosen as the desirable output; and the total discharge of industrial waste water (unit: 10,000 tons), total discharge of industrial waste gas (unit: 100 million cubic meters) and generation of industrial solid waste (unit: 10,000 tons) were used as the undesirable outputs.

\subsection{Core Explanatory Variable}

PM2. $5_{i t}$ denotes the PM2.5 concentration of a certain province $i$ in the year $t$, which was used for measuring the level of haze pollution. As its coefficient $\mathrm{a}_{1}$ measures the impact of haze pollution on the economic development quality, it is the kernel parameter of concern in this paper. After controlling a series of regional characteristic variables, if $a_{1}$ remains significantly negative, it indicates that the haze pollution will degrade the quality of economic development, and vice versa. In addition, this paper also controls the regional and temporal fixed effects, in order to further alleviate the biases of missing variables. Finally, $\varepsilon_{\text {it }}$ represents the error term. Regarding the haze pollution data, unlike the conventional haze pollutants like $\mathrm{SO}_{2}, \mathrm{CO}_{2}, \mathrm{CO}$, TSP, API and PM10 used in the majority of the literature, this paper selects PM2.5 for empirical research, which is the culprit for haze pollution that is attracting the most attention from all sectors of society. This not only supplements the existing literature, but also contributes to the current policy discussions on haze pollution.

\subsection{Control Variables}

With reference to the extant literature, this paper also adopts four control variables in the benchmark regression model, namely the foreign direct investment (FDI), industrial structure (Indus), technological innovation (Innov) and population density (Density), so as to alleviate the biases of missing variables as much as possible. The level of FDI in a region affects its green TFP, and the primary reasons include the "pollution haven" hypothesis [30] and the opposite view of the "pollution halo" hypothesis [31]. Thus, the variable should be considered in the model. Indus is a comprehensive 
influencing factor of TFP proposed by reference [32], which can reflect the industrial layout. In this paper, Indus is calculated in terms of the output value of secondary industry in proportion to GDP. The higher the proportion of secondary industry, the more severe the pollution it brings, which will adversely affect the TFP. Presumably, Indus is negatively correlated with TFP. In addition, factors like Density and Innov are also common variables in the literature [33,34]. In this paper, Density is measured by the number of people per unit area, while Innov is calculated by the number of patents per capita. We presume that Innov is positively correlated with TFP. Meanwhile, a higher Density means there is a greater pressure imposed on the environment. Presumably, this variable is negatively correlated with TFP. Table 1 presents descriptions statistics for the main variables.

Table 1. Descriptive Statistics of Variables.

\begin{tabular}{ccccc}
\hline Variable & Min & Max & Mean & SD \\
\hline TFP & 0.500 & 2.249 & 1.095 & 0.296 \\
PM2.5 & 4.8 & 82.67 & 32.122 & 16.843 \\
Density & 0.040 & 1.288 & 0.483 & 0.266 \\
FDI & 0.008 & 0.263 & 0.483 & 0.266 \\
Innov & 2.654 & 383.68 & 42.099 & 51.350 \\
Indus & 0.240 & 2.022 & 1.203 & 0.337 \\
\hline
\end{tabular}

In analyzing how the haze pollution affects the quality of economic development through the transmission mechanisms, the endogeneity of haze pollution is not a serious issue. During direct analysis of the impact of haze pollution on the economic development quality based on the above benchmark model, however, the endogeneity of haze pollution variables becomes an inevitable issue to discuss. Specifically, on the one hand, environmental pollution may drag down the quality of economic development through channels like the "labor supply loss effect", "counter urbanization effect" and "human capital disruption effect". On the other hand, the quality of economic development itself also affects environmental pollution through the scale effect, technology effect and structure effect. An effective way of alleviating the aforementioned endogeneity problem is to find the appropriate instrumental variables for haze pollution, which is the core explanatory variable. The sought instrumental variables must be highly correlated with the endogenous variable (PM2.5 concentration), while not directly relevant to the explained variable (economic development quality). Precipitation can be used as an instrumental variable for haze pollution because on the one hand, a larger value of precipitation indicates more local rainwater. In the rainy and snowy weathers, air pollution tends to decline remarkably, which is negatively correlated with haze pollution, thus satisfying the correlation hypothesis of valid instrumental variables [35]. On the other hand, precipitation is affected by rainfall and snowfall, both of which are determined by complex meteorological systems and geographical conditions, thereby satisfying the exogeneity hypothesis of valid instrumental variables [36].

In summary, to quantitatively explore the impact of air pollution on the economic development quality, the two-stage least squares (2SLS) regression model in this paper is defined as follows:

$$
\begin{aligned}
& \text { PM2. } 5_{i t}=\beta_{0}+\beta_{1} \text { Rainfall }_{i t}+\gamma_{i}+\mu_{t}+\varepsilon_{i t} \\
& \mathrm{TFP}_{\mathrm{it}}=\mathrm{y}_{0}+\mathrm{y}_{1} \mathrm{PM}_{2} \text {. }_{\mathrm{it}}+\mathrm{y}_{2} \text { Density }_{\mathrm{it}}+\mathrm{y}_{3} \mathrm{FDI}_{\mathrm{it}}+\mathrm{y}_{4} \text { Innov }_{\mathrm{it}}+\mathrm{y}_{5} \text { Indus }_{\mathrm{it}}+\gamma_{\mathrm{i}}+\mu_{\mathrm{t}}+\varepsilon_{\mathrm{it}}
\end{aligned}
$$

where Rainfall ${ }_{\text {it }}$ represents the annual rainfall of a certain province $i$ in the year $t$. In the 2SLS model, it is an instrumental variable of PM2.5 concentration, the haze pollution variable. All the other variables are identical to those used in the benchmark model Formula (1).

In this paper, the panel data from 30 provinces, autonomous regions and municipalities (Tibetan region is excluded due to severe data missing) of China between 2004-2016 are utilized. Regarding haze pollution, we used the satellite raster data of global average PM concentration published by the Socioeconomic Data and Applications Center of Columbia University by referring to Van's 
methodology [37]. With the aid of ArcGIS software, the above data were analyzed into the average annual concentration of surface PM2.5 for China's 30 province-level administrative regions from 2004 to 2016. The rest of the raw data were from the China Statistical Yearbooks, China Environmental Statistics Yearbooks, the official websites of National Bureau of Statistics and the provincial, municipal statistics bureaus, as well as the GTA CSMAR database. All the value variables in this paper are processed for to account for inflation with 2004 as the base year.

\section{Analyses of Empirical Results}

\subsection{Benchmark Regression}

The columns (1), (2) in Table 2 present the fixed effect estimations for the designed model. The use of panel data fixed effect model is based primarily on the following two aspects: On the one hand, since the chi-square value in Hausman test report is 45.324 , and its corresponding P value is 0.000 , the random effect model is rejected; on the other hand, the random effect assumes that the individual fixed effect term is irrelevant to the explanatory variables, which often hardly holds in practice. According to the results in column 1 , haze pollution is significantly negatively correlated with the quality of regional economic development. The results in column 2, after controlling a series of regional characteristic variables, still show a significant negative correlation of haze pollution with the quality of regional economic development. Considering that the economic development mode affects both the quality of economic development and the haze pollution, especially that the imbalance of industrial structure is a major reason for the intensification of haze pollution in China, failure to control these factors effectively may lead to biases of missing variables, which in turn affects the reliability of research results. In column 3 , the proportion of secondary production is added, in order to control the impact of industrial structure. Its results demonstrate that a significant negative correlation remains between the haze pollution and the urban economic development quality.

Table 2. The impact of haze pollution on the quality of economic development.

\begin{tabular}{|c|c|c|c|c|c|c|}
\hline & (1) & (2) & (3) & (4) & (5) & (6) \\
\hline & \multicolumn{3}{|c|}{ Fixed Effect } & \multicolumn{3}{|c|}{ 2SLS } \\
\hline & TFP & TFP & TFP & $\begin{array}{c}\text { PM2.5 } \\
\text { Stage One }\end{array}$ & $\begin{array}{c}\text { TFP } \\
\text { Stage Two }\end{array}$ & TFP \\
\hline PM2.5 & $\begin{array}{c}-0.006^{* *} \\
(-2.58)\end{array}$ & $\begin{array}{c}-0.005^{* *} \\
(-2.28)\end{array}$ & $\begin{array}{c}-0.005^{* *} \\
(-2.45)\end{array}$ & & $\begin{array}{c}-0.050 * * * \\
(-2.61)\end{array}$ & $\begin{array}{l}-0.545 \\
(-1.23)\end{array}$ \\
\hline PM2. $5^{2}$ & & & & & & $\begin{array}{l}0.007 \\
(1.12)\end{array}$ \\
\hline Rainfall & & & & $\begin{array}{c}-1.974 * * \\
(-2.40)\end{array}$ & & \\
\hline Density & & $\begin{array}{c}-0.0401 \\
(-0.32)\end{array}$ & $\begin{array}{c}-0.0960 \\
(-0.77)\end{array}$ & & $\begin{array}{l}-0.152 \\
(-1.23)\end{array}$ & $\begin{array}{l}-0.160 \\
(-1.29)\end{array}$ \\
\hline FDI & & $\begin{array}{c}-1.381^{* * * *} \\
(-2.83)\end{array}$ & $\begin{array}{c}-1.263^{* * *} \\
(-2.63)\end{array}$ & & $\begin{array}{c}-1.311^{* * *} \\
(-2.73)\end{array}$ & $\begin{array}{c}-1.381^{* * *} \\
(-2.85)\end{array}$ \\
\hline Innov & & $\begin{array}{c}0.008^{* * *} \\
(3.67)\end{array}$ & $\begin{array}{c}0.005^{* *} \\
(2.52)\end{array}$ & & $\begin{array}{c}0.005^{* *} \\
(2.56)\end{array}$ & $\begin{array}{c}0.005^{* *} \\
(2.43)\end{array}$ \\
\hline Indus & & & $\begin{array}{c}-0.162^{* * *} \\
(-3.59)\end{array}$ & & $\begin{array}{c}-0.145^{* * *} \\
(-3.20)\end{array}$ & $\begin{array}{c}-0.143^{* * *} \\
(-3.17)\end{array}$ \\
\hline _cons & $\begin{array}{c}1.301^{* * *} \\
(16.19)\end{array}$ & $\begin{array}{c}1.335^{* * *} \\
(13.47)\end{array}$ & $\begin{array}{c}1.571^{* * * *} \\
(13.36)\end{array}$ & $\begin{array}{c}45.22 * * * \\
(8.28)\end{array}$ & $\begin{array}{c}3.003 * * * \\
(4.81)\end{array}$ & $\begin{array}{l}11.02 \\
(1.53)\end{array}$ \\
\hline$R^{2}$ & 0.0182 & 0.0752 & 0.1076 & 0.0158 & 0.1095 & 0.1126 \\
\hline$N$ & 390 & 390 & 390 & 390 & 390 & 390 \\
\hline
\end{tabular}


Columns (4) to (6) in Table 2 display the estimation results with the two-stage least squares (2SLS), since the endogeneity problem of haze pollution to TFP is taken into consideration. In this regard, the instrumental variables are subjected to rationality tests, including the underidentification test and the weak instrumental variable test. Initially, according to the LM statistic of 6.357 in the underidentification test, and its corresponding $p$ value of 0.0117 , the hypothesis of non-correlation between instrumental and endogenous variables can be rejected at the $5 \%$ level. Next, the selected instrumental variables are tested for weak variables. The reported Cragg-Donald F statistic is 6.382 , and its corresponding $10 \%$ critical value is 16.38 . Therefore, it is impossible to reject the null hypothesis of strong correlations between instrumental and endogenous variables. This suggests that the selected instrumental variables are correlated strongly with the endogenous variables. Finally, Sargan's results demonstrate that the model conforms to the exact identification and does not require an overidentification test. To sum up, the instrumental variables selected in this paper are rather reasonable. On the whole, the results of first-stage regression suggest that the precipitation reduces the haze pollution at a $1 \%$ significance level. According to the results of second-stage regression, the impact of haze pollution on the quality of China's economic development resembles the benchmark regression reported in Table 2, both in terms of direction and significance. This further verifies the adverse effect of haze pollution on the quality of China's economic development. However, from a quantitative point of view, the absolute estimated coefficient of haze pollution has increased nearly ten times compared to the benchmark regression. This suggests that the potential endogeneity problem tends to cause underestimation of the adverse effect of haze pollution on China's economic development quality. According to the linear regression results of the benchmark model, on the whole, haze pollution has degraded the quality of China's economic development strikingly. This leaves us with a question: did haze pollution adversely impact the quality of China's economic development just from the beginning, or did this negative impact appear gradually after the haze pollution reached a certain level? Extensive studies have found that the destructiveness of environmental pollution depends on its severity to a large extent, and that there may be a Kuznets curve effect regarding its impact on economic development. In this respect, we empirically tested the above assumption by further adding the quadratic term of PM2.5 concentration into the benchmark regression model. According to our findings, there is no inverted U-shaped relationship between PM2.5 concentration and quality of economic development, and the impact of haze pollution has been only linear to the economic development quality for China in recent years. This is probably linked to the time interval selected in this paper.

Regarding control variables, regional FDI has a significant negative correlation with TFP, which agrees with the "pollution haven" hypothesis. This hypothesis has been prevailing in FDI academia [38]. Given the high environmental pollution costs, developed countries will transfer some pollution-intensive firms to those developing countries with loose environmental regulations, so as to cut the pollution control costs. Developing countries, on the other hand, will introduce some pollution-intensive industries and low-tech industries by lowering the level of environmental regulations, so as to increase their competitiveness in attracting foreign investment. As a result, the environmental pollution will be exacerbated to hinder the enhancement of green TFP. This paper provides evidence for the "pollution haven" hypothesis from China. In terms of other aspects, Indus is significantly negatively correlated with TFP; Innov is significantly positively correlated with TFP; and Density is insignificantly negatively correlated with TFP, all of which are basically consistent with the predictions.

\subsection{Analysis of Transmission Mechanisms}

Results of the foregoing studies show that the haze pollution is negatively influential to the quality of China's economic development. So, what caused this phenomenon? In other words, what are the transmission mechanisms for haze pollution that affect the quality of China's economic development? Based on the foregoing hypotheses, this paper studies the transmission mechanisms whereby haze pollution affects China's economic development quality from three aspects: Labor loss, counter 
urbanization and human capital disruption. First of all, haze pollution can affect China's economic development through a loss of labor. To verify this mechanism, we selected the proportion of employed population to total population as the proxy variable for labor (Labor). In Table 3, the corresponding empirical regressions are reported. As can be seen, the regression coefficient of labor variable in column 1 is significantly positive, indicating that the labor force promotes the enhancement of economic quality. To alleviate the endogeneity problem, its impact on the quality of economic development is examined in column 2 of Table 3 by using the quantity of one-phase lagging labor. The two-stage least squares estimation in column 3 reveals a significant negative correlation of the haze pollution with the labor, indicating that the haze pollution has caused drastic depletion of the local labor supply. Secondly, haze pollution can affect China's economic development through counter urbanization. To verify this mechanism, the proportion of non-agricultural population to total population is selected as a proxy variable for urbanization (Urban). In Table 3, the corresponding empirical regressions are reported. As can be seen, the regression coefficient of urbanization variable in column 4 is significantly positive, indicating that the urbanization promotes the enhancement of economic quality. Noteworthy is that the higher the quality of economic development, the more likely it is to attract population agglomeration, which may adversely affect the urbanization process. To alleviate this endogeneity problem, the impact of urbanization on the economic development quality is examined in column 4 of Table 3 by using the one-phase lagging urbanization. For column 5, the 2SLS estimation is still used. The significantly negative coefficient of urbanization variable indicates that the haze pollution has slowed down the process of urbanization. Finally, another major mechanism for haze pollution to affect the quality of China's economic development is by impacting the human capital accumulation. In this paper, the average years of education widely used in the literature is chosen as a proxy variable for human capital (Capital). With this variable, the human capital mechanism through which the haze pollution affects the quality of China's economic development is examined empirically. As shown in Table 3, the human capital transmission mechanism can be verified effectively. That is, the accumulation of human capital has enhanced the quality of economic development, while the haze pollution has lowered the human capital strikingly.

Table 3. Verification of Transmission Mechanisms.

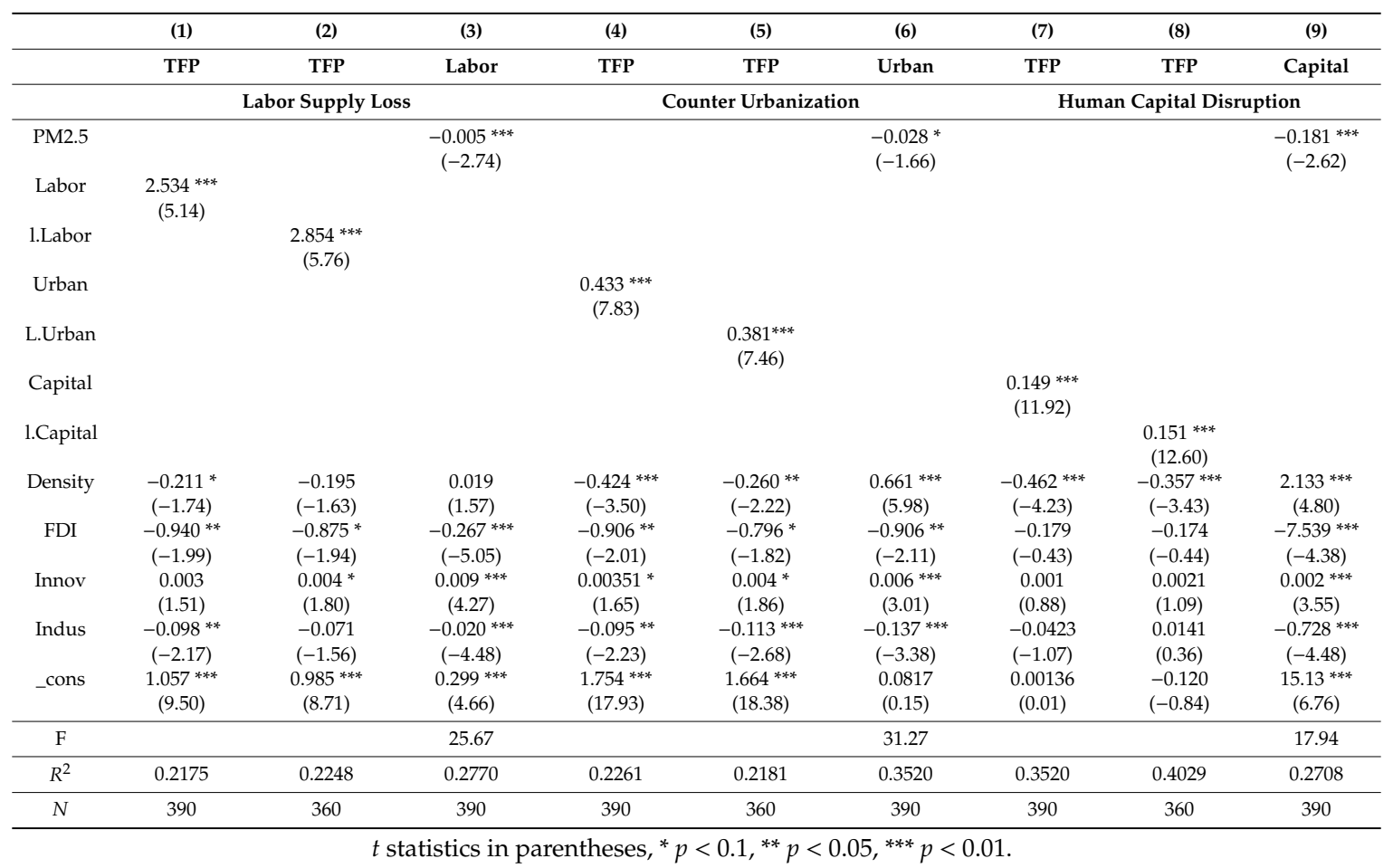




\subsection{Robustness Analysis}

To further guarantee the reliability of research conclusions, we also performed a series of robustness tests based on the instrumental variable regression reported in column 5 of Table 2. Table 4 details the corresponding results. Since the aforementioned variables only target the core explanatory variables, a related concern is the probable endogeneity problems with the control variables caused by "reverse causality". To eliminate this adverse effect, all the control variables are lagged by one phase in column 1 of Table 4, and the regression results are basically unchanged as well. For a better comparability of study samples, the municipality samples are excluded, and only the provincial-level samples are retained. The regression results are reported in column 2 of Table 4, which show high consistency with the benchmark scenario. Another potential problem is the close correlation of PM2.5 concentration, a core explanatory variable, with the $\mathrm{SO}_{2}$ and soot emissions. As pollutants, $\mathrm{SO}_{2}$ and soot may also produce an impact on the quality of economic development, thereby leading to biases of missing variables. To this end, we further controlled the $\mathrm{SO}_{2}$ and soot emissions per unit area, in order to identify the impact of PM2.5 pollution on the quality of China's economic development accurately. Compared to the column 5 in Table 2, the coefficient and significance in the column 3 of Table 4 are basically unchanged. To examine the sensitivity of the regression results to the model settings, an empirical analysis is carried out using a logarithmic model, which finds that the negative impact of haze pollution on the economic development quality still exists at significant levels. Furthermore, $0.5 \%$ of samples with the highest and lowest PM2.5 concentrations are excluded from the column 5 of Table 4, in order to examine the influence of haze pollution outliers on the regression results. Again, the research results basically remain unchanged. Finally, GDP per capita is also used by some research for measuring the quality of economic development. As shown in the column 6 of Table 4, the haze pollution remains negatively correlated with the GDP per capita.

Table 4. Robustness Tests.

\begin{tabular}{|c|c|c|c|c|c|c|}
\hline & (1) & (2) & (3) & (4) & (5) & (6) \\
\hline & TFP & TFP & TFP & $\ln$ TFP & TFP & GDP \\
\hline & $\begin{array}{c}\text { Lag Control } \\
\text { Variable }\end{array}$ & $\begin{array}{c}\text { Delete } \\
\text { Municipality }\end{array}$ & Control $\mathrm{SO}_{2}$ & $\begin{array}{l}\text { Absolute } \\
\text { Value }\end{array}$ & Delete $0.5 \%$ & $\begin{array}{c}\text { GDP as } \\
\text { Explained } \\
\text { Variable }\end{array}$ \\
\hline PM2.5 & $\begin{array}{c}-0.068^{* * *} \\
(-3.62)\end{array}$ & $\begin{array}{c}-0.054^{* * *} \\
(-2.67)\end{array}$ & $\begin{array}{c}-0.047^{* * *} \\
(-2.61)\end{array}$ & & $\begin{array}{c}-0.059^{* * *} \\
(-2.61)\end{array}$ & $\begin{array}{c}-0.598^{* * *} \\
(-4.27)\end{array}$ \\
\hline $\ln \mathrm{PM} 2.5$ & & & & $\begin{array}{c}-1.499 * * \\
(-2.51)\end{array}$ & & \\
\hline Density & $\begin{array}{l}0.028 \\
(0.22)\end{array}$ & $\begin{array}{c}-0.240 * \\
(-1.82)\end{array}$ & $\begin{array}{c}-0.247^{* *} \\
(-2.03)\end{array}$ & $\begin{array}{l}-0.094 \\
(-0.90)\end{array}$ & $\begin{array}{l}-0.152 \\
(-1.23)\end{array}$ & $\begin{array}{c}5.668^{* * * *} \\
(6.30)\end{array}$ \\
\hline FDI & $\begin{array}{c}-1.564^{* * *} \\
(-3.31)\end{array}$ & $\begin{array}{c}-1.698^{* * *} \\
(-3.10)\end{array}$ & $\begin{array}{c}-1.077^{* *} \\
(-2.39)\end{array}$ & $\begin{array}{c}-1.049 * * \\
(-2.58)\end{array}$ & $\begin{array}{c}-1.311^{* * * *} \\
(-2.73)\end{array}$ & $\begin{array}{c}-18.89 * * * \\
(-5.41)\end{array}$ \\
\hline Innov & $\begin{array}{c}0.004^{* *} \\
(2.14)\end{array}$ & $\begin{array}{c}0.004 \text { * } \\
(1.71)\end{array}$ & $\begin{array}{l}0.003 \\
(1.65)\end{array}$ & $\begin{array}{c}0.005^{* * *} \\
(2.65)\end{array}$ & $\begin{array}{c}0.005^{* *} \\
(2.56)\end{array}$ & $\begin{array}{c}0.010 * * * \\
(6.30)\end{array}$ \\
\hline Indus & $\begin{array}{l}-0.061 \\
(-1.25)\end{array}$ & $\begin{array}{c}-0.152^{* * *} \\
(-3.16)\end{array}$ & $\begin{array}{c}-0.103^{* *} \\
(-2.31)\end{array}$ & $\begin{array}{c}-0.111^{* * *} \\
(-2.90)\end{array}$ & $\begin{array}{c}-0.145^{* * * *} \\
(-3.20)\end{array}$ & $\begin{array}{c}-2.173^{* * *} \\
(-6.61)\end{array}$ \\
\hline L.x16 & & & $\begin{array}{c}-0.003^{* * *} \\
(-4.47)\end{array}$ & & & \\
\hline _cons & $\begin{array}{c}3.419^{* * * *} \\
(5.58)\end{array}$ & $\begin{array}{c}3.223^{* * *} \\
(4.84)\end{array}$ & $\begin{array}{c}3.164^{* * * *} \\
(5.44)\end{array}$ & $\begin{array}{c}5.222^{* * * *} \\
(2.64)\end{array}$ & $\begin{array}{c}3.293^{* * *} \\
(4.48)\end{array}$ & $\begin{array}{c}23.16^{* * *} \\
(5.11)\end{array}$ \\
\hline $\mathrm{F}$ & 33.71 & 22.79 & 37.58 & 27.38 & 27.53 & 16.69 \\
\hline$R^{2}$ & 0.1048 & 0.1139 & 0.1882 & 0.1018 & 0.1095 & 0.4426 \\
\hline$N$ & 360 & 338 & 360 & 390 & 390 & 390 \\
\hline
\end{tabular}

$t$ statistics in parentheses, ${ }^{*} p<0.1,{ }^{* *} p<0.05,{ }^{* * *} p<0.01$. 


\subsection{Heterogeneity Analysis}

The Chinese Government has taken environmental management to an unprecedented level, and made pollution prevention one of the three major battles for winning a well-off society in an all-round way. The government called for efforts to address prominent environmental issues, continue to implement the atmospheric pollution control campaigns and to win the battle for the defense of the blue sky, so as to promote green development. Given China's vast territory, local governments show distinct differences in the enforcement of environmental regulations, which may affect the relationship between the haze pollution and the economic development quality. With reference to previous research [39], this paper classifies the environmental regulations into the investment type and the expense type depending on the perspective of capital investment. Initially, the proportion of industrial pollution control investment and emission charges in GDP was calculated for various provinces, followed by the calculation of the median value of the proportion. Using this median as the boundary, regions were divided into those with high environmental management efforts and low environmental management efforts. Afterwards, econometric regression was performed on them separately. The columns (1)-(4) in Table 5 present the regression results. Clearly, the destructive effect of haze pollution on the economic development quality is present only in the regions with low environmental management efforts.

Under the Chinese-style fiscal decentralization system, local governments are facing both the core task of developing economy and the sustainability goal of protecting the environment. The local governments' awareness and behavior of environmental protection are affected by fiscal decentralization. The impact of haze pollution on the quality of economic development may vary by the degree of fiscal decentralization. In this paper, the proportion of a region's total budgetary fiscal expenditure in the country's total budgetary fiscal expenditure is taken as a measure of fiscal decentralization degree, and then the median value of the proportion is calculated. Using this median as the boundary, regions are divided into those with high fiscal decentralization and low fiscal decentralization. Afterwards, econometric regression is performed on them separately. The columns (5)-(6) in Table 5 present the regression results. As can be seen, the destructive effect of haze pollution on economic development quality is present only in the regions with high fiscal decentralization.

Table 5. Heterogeneity Analysis.

\begin{tabular}{ccccccc}
\hline & $\mathbf{( 1 )}$ & $\mathbf{( 2 )}$ & $\mathbf{( 3 )}$ & $\mathbf{( 4 )}$ & $\mathbf{( 5 )}$ & $\mathbf{( 6 )}$ \\
\hline & $\begin{array}{c}\text { Low } \\
\text { Pollutant } \\
\text { Discharge }\end{array}$ & $\begin{array}{c}\text { High } \\
\text { Pollutant } \\
\text { Discharge }\end{array}$ & $\begin{array}{c}\text { Small } \\
\text { Investment }\end{array}$ & $\begin{array}{c}\text { Large } \\
\text { Investment }\end{array}$ & $\begin{array}{c}\text { Great Fiscal } \\
\text { Decentralization }\end{array}$ & $\begin{array}{c}\text { Small Fiscal } \\
\text { Decentralization }\end{array}$ \\
\hline PM2.5 & $-0.080^{* * *}$ & -0.016 & $-0.067^{* * *}$ & -0.008 & $-0.088^{* * *}$ & 0.046 \\
& $(-3.72)$ & $(-0.66)$ & $(-2.89)$ & $(-0.31)$ & $(-3.48)$ & $(1.61)$ \\
Density & -0.0543 & -0.165 & $-0.320^{* *}$ & 0.139 & $-0.282^{*}$ & $0.661^{* *}$ \\
& $(-0.40)$ & $(-0.87)$ & $(-2.22)$ & $(0.65)$ & $(-1.90)$ & $(2.48)$ \\
FDI & -0.529 & $-5.818^{* * *}$ & -0.348 & $-3.981^{* * *}$ & $-1.435^{* *}$ & 0.077 \\
& $(-1.20)$ & $(-4.09)$ & $(-0.66)$ & $(-4.35)$ & $(-2.26)$ & $(0.10)$ \\
Innov & $0.005^{* *}$ & -0.003 & $0.004^{*}$ & $0.001^{*}$ & $0.005^{*}$ & 0.005 \\
& $(2.31)$ & $(-0.48)$ & $(1.80)$ & $(1.98)$ & $(1.82)$ & $(1.62)$ \\
Indus & $-0.164^{* * *}$ & $-0.220^{* * *}$ & $-0.124^{* *}$ & $-0.167^{* *}$ & $-0.135^{* *}$ & -0.128 \\
& $(-3.27)$ & $(-3.04)$ & $(-2.37)$ & $(-2.14)$ & $(-2.35)$ & $(-1.58)$ \\
cons & $3.924^{* * *}$ & $2.178^{* * *}$ & $3.514^{* * *}$ & $1.668^{*}$ & $4.331^{* * *}$ & -0.559 \\
& $(5.64)$ & $(2.68)$ & $(4.68)$ & $(1.87)$ & $(5.26)$ & $(-0.59)$ \\
\hline $\mathrm{F}$ & 35.45 & 11.49 & 27.91 & 11.78 & 17.53 & 41.49 \\
\hline$R^{2}$ & 0.1795 & 0.1832 & 0.1200 & 0.2412 & 0.1223 & 0.2169 \\
\hline$N$ & 244 & 146 & 254 & 136 & 251 & 139 \\
\hline
\end{tabular}

The above empirical results indicate that the environmental regulations can mitigate the damaging effect of haze pollution on the economic development quality. So through what mechanisms do environmental regulations play their positive role? This paper next explores the relevant principles 
through the effects of environmental regulations on the three transmission channels of haze pollution. Depending on the aforementioned proportion of emission charges in GDP, various provinces were classified into regions with high environmental management efforts and low environmental management efforts. Then, econometric regression was performed separately on the three channels. As shown in Table 6, in regions with low environmental management efforts, haze pollution is significantly negatively correlated with all the three variables of Labor, Urban and Capital, while in regions with high environmental management efforts, such negative correlations are all insignificant. It has been widely recognized by academia that strict environmental regulations can improve the eco-environment and the health of residents [40]. Strengthening of environmental regulations not only can impact the quality of economic growth by influencing the health and effective labor input of residents, but also can attract more high-end talented individuals through the improvement of eco-environment. As the above results suggest, environmental regulations promote the sustainable economic growth precisely by mitigating the "labor supply loss effect", "counter urbanization effect" and "human capital disruption effect" of the haze pollution.

Table 6. Environmental Regulations and Conduction Mechanism.

\begin{tabular}{ccccccc}
\hline & $\mathbf{( 1 )}$ & $\mathbf{( 2 )}$ & $\mathbf{( 3 )}$ & $\mathbf{( 4 )}$ & $\mathbf{( 5 )}$ & $\mathbf{( 6 )}$ \\
\hline \multirow{2}{*}{ Labor } & $\begin{array}{c}\text { Less Sewage Charge } \\
\text { Urban }\end{array}$ & Capital & Labor & $\begin{array}{c}\text { Large Sewage Charge } \\
\text { Urban }\end{array}$ & Capital \\
\hline PM2.5 & $-0.010^{* * *}$ & $-0.022^{*}$ & $-0.280^{* *}$ & -0.001 & -0.003 & -0.010 \\
& $(-3.37)$ & $(-2.26)$ & $(-3.17)$ & $(-0.36)$ & $(-0.52)$ & $(-0.09)$ \\
Density & 0.022 & $0.269^{* * *}$ & $1.258^{*}$ & 0.023 & $0.302^{* * *}$ & $2.658^{* *}$ \\
& $(1.21)$ & $(4.41)$ & $(2.30)$ & $(1.55)$ & $(5.30)$ & $(3.16)$ \\
FDI & $-0.169^{*}$ & $-0.483^{*}$ & $-6.149^{* *}$ & $-0.202^{* *}$ & $-0.987^{* * *}$ & $-13.12^{* * *}$ \\
& $(-2.45)$ & $(-2.17)$ & $(-3.07)$ & $(-3.11)$ & $(-4.06)$ & $(-3.66)$ \\
Innov & $0.008^{*}$ & $0.001^{* *}$ & $0.003^{* *}$ & $0.002^{* * *}$ & $0.006^{* *}$ & $0.007^{*}$ \\
& $(2.58)$ & $(2.66)$ & $(3.12)$ & $(4.60)$ & $(3.38)$ & $(2.28)$ \\
Indus & $-0.025^{* * *}$ & $-0.064^{* *}$ & $-0.522^{* *}$ & -0.010 & $-0.070^{* *}$ & $-0.931^{* *}$ \\
& $(-3.70)$ & $(-2.93)$ & $(-2.62)$ & $(-1.93)$ & $(-3.38)$ & $(-3.03)$ \\
cons & $0.474^{* * *}$ & $1.214^{* * *}$ & $18.55^{* * *}$ & $0.128^{*}$ & $0.545^{*}$ & $9.345^{* *}$ \\
& $(4.83)$ & $(3.82)$ & $(6.49)$ & $(2.04)$ & $(2.31)$ & $(2.68)$ \\
\hline$R^{2}$ & 0.2286 & 0.2458 & 0.2326 & 0.3132 & 0.5144 & 0.3603 \\
\hline$N$ & 254 & 254 & 254 & 136 & 136 & 136 \\
\hline
\end{tabular}

According to the empirical results in Table 5, the degree of fiscal decentralization is an important influencing factor of the haze pollution effects. Similarly, to clarify the relevant mechanisms, econometric regression was performed separately on the three channels of haze pollution. As shown in Table 7, in the regions with high fiscal decentralization, the haze pollution is significantly negatively correlated with Labor and Capital, while in the regions with low fiscal decentralization, such negative correlations are insignificant. The core of Chinese-style fiscal decentralization is the economic decentralization and political centralization. Encouraged by the political promotion, the central government uses local GDP growth as a standard for assessing local officials, with the aim of stimulating the economic growth. Meanwhile, the local officials have made economic construction their main priority, which has led to the "promotion tournament" phenomenon that is unique to China. The extensive growth mode of factor input expansion is prone to problems, such as compromised environmental quality, insufficient public service supply and declining human capital stock. Such negative effects may be stronger with a heightening degree of fiscal decentralization, where the haze pollution produces a more severe negative impact on the quality of economic development. 
Table 7. Fiscal Decentralization and Conduction Mechanism.

\begin{tabular}{ccccccc}
\hline & $\mathbf{( 1 )}$ & $\mathbf{( 2 )}$ & $\mathbf{( 3 )}$ & $\mathbf{( 4 )}$ & $\mathbf{( 5 )}$ & $\mathbf{( 6 )}$ \\
\hline \multirow{2}{*}{ High Fiscal Decentralization } & \multicolumn{2}{c}{ Low Fiscal Decentralization } \\
& Labor & Urban & Capital & Labor & Urban & Capital \\
\hline PM2.5 & $-0.006^{*}$ & -0.002 & $-0.092^{*}$ & -0.001 & -0.011 & -0.049 \\
& $(-2.08)$ & $(-1.22)$ & $(-2.35)$ & $(-0.79)$ & $(-0.48)$ & $(-0.50)$ \\
Density & $0.051^{*}$ & $0.429^{* * *}$ & $2.306^{* * *}$ & 0.006 & $0.226^{* * *}$ & $2.349^{* * *}$ \\
& $(2.13)$ & $(6.25)$ & $(4.53)$ & $(0.57)$ & $(4.09)$ & $(3.37)$ \\
FDI & -0.08 & -0.421 & -0.637 & -0.045 & -0.266 & $-6.691^{* *}$ \\
& $(-0.98)$ & $(-1.65)$ & $(-0.34)$ & $(-1.10)$ & $(-1.41)$ & $(-2.80)$ \\
Innov & $0.002^{* * *}$ & $0.005^{* * *}$ & $0.008^{* * *}$ & 0.001 & 0.001 & 0.002 \\
& $(3.93)$ & $(3.37)$ & $(8.34)$ & $(0.93)$ & $(1.63)$ & $(0.21)$ \\
Indus & $-0.028^{* * *}$ & $-0.076^{* *}$ & $-0.722^{* * *}$ & 0.006 & 0.027 & $0.550^{*}$ \\
& $(-3.35)$ & $(-3.16)$ & $(-4.00)$ & $(1.27)$ & $(1.25)$ & $(2.01)$ \\
cons & $0.370^{* * *}$ & 0.590 & $12.32^{* * *}$ & $0.118^{*}$ & $0.628^{*}$ & $8.169^{*}$ \\
& $(3.47)$ & $(1.96)$ & $(5.51)$ & $(2.07)$ & $(2.43)$ & $(2.50)$ \\
\hline$R^{2}$ & 0.3788 & 0.4668 & 0.6201 & 0.1255 & 0.1262 & 0.1238 \\
\hline$N$ & 206 & 206 & 206 & 184 & 184 & 184 \\
\hline
\end{tabular}

\section{Conclusions and Policy Recommendations}

Environmental protection and economic development are eternal concerns for all of mankind. In particular, with the entry of China's development into a new era, the issue has attracted wider attention from all walks of life. How can we fight the battle against pollution? How should we promote the high-quality development of economy through governmental management of environment? Achieving such a win-win goal is inseparable from a systematic grasp of the relationship between environmental pollution and economic development. The majority of extant studies, however, focus only on the unidirectional relationship of the impact of economic development on haze pollution, while ignoring the feedback mechanism of the impact of haze pollution on economic development. In a literature study closest in scope to this paper [10], the potential endogeneity problems were not resolved effectively, because of a failure to find the instrumental variables for haze pollution. In addition, the literature lacked discussion of the mechanism whereby the haze pollution affected the economic development. To this end, this paper systematically investigates the impact of haze pollution on the quality of China's economic development, as well as its transmission mechanisms. This is accomplished by taking total factor productivity as a proxy variable for the economic development quality, and by using China's PM2.5 haze data at the provincial level over a span of 13 years from 2004 to 2016. Furthermore, this paper innovatively uses precipitation as an instrumental variable for mitigating the endogeneity of haze pollution, and employs 2SLS for estimating the impact of haze pollution on the quality of economic development. The main conclusions of this paper are as follows: The intensification of haze pollution degrades the quality of China's economic development strikingly; the loss of labor supply, counter urbanization and human capital disruption are the three major transmission channels through which haze pollution affects the quality of China's economic development; strengthening government's environmental management is effective in reducing the haze pollution to upgrade the quality of economic development; and Chinese-style fiscal decentralization is a major reason for the negative economic effect of haze pollution. These research conclusions have profound policy implications. For a long time, in the grand context of economic construction centricity, a common view on the relationship between economic development and haze pollution has been that the reduction of haze pollution inevitably harms economic development. As a result, some places have adopted a "laissez-faire attitude" towards haze pollution. Given the limited carrying capacity of the environment, however, boosting the economy persistently through continuous pollutant emissions is destined to be unsustainable. Today, China is already confronting the dual challenges of severe 
environmental deterioration and the urgent need for enhancement of economic development quality. Extensive economic growth is the culprit, leading to the exacerbating haze pollution. Haze pollution in turn further affects the quality of China's economic development through channels like labor loss, counter urbanization and human capital disruption. To resolve such a vicious circle and dilemma fundamentally, the sole measure is the implementation of a reasonable and effective governmental policy on environmental management. By doing so, the production factors can flow continuously away from inefficient high energy consumption, from high emission sectors to the efficient low energy consumption, low emission sectors. In addition, the economic structure can be optimized continuously and the total factor productivity and economic development quality can be improved constantly. In this way, the win-win goal of continuous reduction of haze pollution and the transformation of economic development mode to high-quality development can be attained. Also, this is precisely the core implication of China's supply-side structural reform in dealing with the eternal relationship between environmental protection and economic development.

Author Contributions: Conceptualization, Q.Z. and C.-H.Y.; Methodology, Q.Z.; Formal Analysis: Q.Z.; Writing, Q.Z. and C.-H.Y. All authors have read and agreed to the published version of the manuscript.

Funding: Guangdong Province Philosophy and Social Science Planning 2019 General Project "Research on Industrial Policy Transformation to Promote High Quality Development of Manufacturing Industry" (Approval number: GD19CYJ01).

Conflicts of Interest: The authors declare no conflict of interest.

\section{References}

1. Shafik, N. Economic development and environmental quality: An econometric analysis. Oxf. Econ. Pap. 1994, 46, 757-773. [CrossRef]

2. Friedl, B.; Getiner, M. Determinants of $\mathrm{CO}_{2}$, emissions in a small open economy. Ecol. Econ. 2003, 45, $133-148$. [CrossRef]

3. Ebenstein, A.; Fan, M.; Greenstore, M.; He, G.; Yin, P.; Zhou, M. Growth, pollution and life expectancy: China from 1991-2012. Am. Econ. Rev. 2015, 105, 226-231. [CrossRef]

4. Ouyanga, X.; Shao, Q.; Zhu, X.; Hea, Q.; Xianga, C.; Weia, G. Environmental regulation, economic growth and air pollution: Panel threshold analysis for OECD countries. Sci. Total Environ. 2019, 657, 234-241. [CrossRef] [PubMed]

5. Su, Y.; Lu, C.; Lin, X.; Zhong, L.; Gao, Y.; Lei, Y. Analysis of Spatio-temporal Characteristics and Driving Forces of Air Quality in the Northern Coastal Comprehensive Economic Zone, China. Sustainability 2020, 12, 536. [CrossRef]

6. Lopez, R. The environment as a factor of production: The effects of economic growth and trade liberalization. J. Environ. Econ. Manag. 1994, 27, 163-184. [CrossRef]

7. Giannadaki, D.; Giannakis, E.; Pozzer, A.; Lelieveld, J. Estimating health and economic benefits of reductions in air pollution from agriculture. Sci. Total Environ. 2018, 622-623, 1304-1316. [CrossRef]

8. Kampa, M.; Castanas, E. Human Health Effects of Air Pollution. Environ. Pollut. 2008, 151, $362-367$. [CrossRef]

9. Yang, G.; Wang, Y.; Zeng, Y. Rapid health transition in China, 1990-2010: Findings from the Global Burden of Disease Study 2010. Lancet 2013, 381, 1987-2015. [CrossRef]

10. Hao, Y.; Peng, H.; Temulun, T.; Liu, L.; Mao, J.; Lu, Z.; Chen, H. How harmful is air pollution to economic development? New evidence from PM2.5 concentrations of Chinese cities. J. Clean Prod. 2017, 172, 743-757. [CrossRef]

11. Zhang, Y.; Jiang, Y.; Guo, Y. The effects of haze pollution on stock performances: Evidence from China. Appl. Econ. 2017, 49, 2226-2237. [CrossRef]

12. Chen, J.C.; Wang, G.; Chen, R.; Liu, X.; Wei, G. Indirect Economic Impact Incurred by Haze Pollution: An Econometric and Input-Output Joint Model. Public Health 2019, 16, 2328. [CrossRef] [PubMed]

13. Hanlon, W.W. Coal Smoke and the Costs of the Industrial Revolution; NBER Working Paper No. 22921; National Bureau of Economic Research: Cambridge, MA, USA, 2016. [CrossRef] 
14. Cole, M.A.; Elliott, R.J.; Okubo, T. Trade, Environmental Regulations and Industrial Mobility: An Industry-level Study of Japan. Ecol. Econ. 2010, 69, 1995-2002. [CrossRef]

15. Knittel, C.R.; Millera, D.L.; Sanders, N.J. Caution, Drivers! Children Present: Traffic, Pollution and Infant Health. Rev. Econ. Stat. 2016, 98, 350-366. [CrossRef]

16. Kenneth, Y.; Chay, M.G. The Impact of Air Pollution on Infant Mortality: Evidence from Geographic Variation in Pollution Shocks Induced by a Recession. Q. J. Econ. 2003, 118, 1121-1167.

17. He, J.; Liu, H.; Salvo, A. Severe Air Pollution and Labor Productivity: Evidence from Industrial Towns in China. Am. Econ. J. Appl. Econ. 2019, 11, 173-201. [CrossRef]

18. Deryugina, T.; Heutel, G.; Miller, N.H. The Mortality and Medical Costs of Air Pollution: Evidence from Changes in Wind Direction. Am. Econ. Rev. 2019, 109, 4178-4219. [CrossRef]

19. Lua, X.; Lin, C.; Li, W.; Chen, Y.; Huang, Y.; Funga, J.; Lau, C.H.; Alexis, K.H. Analysis of the adverse health effects of PM2.5 from 2001 to 2017 in China and the role of urbanization in aggravating the health burden. Total Environ. 2019, 652, 683-695. [CrossRef]

20. Hausman, J.A.; Ostro, B.D.; Wise, D.A. Air pollution and lost work. Natl. Bureau Econ. Res. $1984,1263$. [CrossRef]

21. Rema, H.; Paulina, O. The effect of pollution on labor supply: Evidence from a natural experiment in Mexico City. J. Public Econ. 2015, 122, 68-79.

22. Bosi, S.; Desmarchelier, D.; Ragot, L. Pollution effects on labor supply and growth. Int. J. Econ. Theory 2015, 11, 371-388. [CrossRef]

23. Carson, R.T.; Koundouri, P.; Nauges, C. Arsenic mitigation in Bangladesh: A Household Labor market approach. Am. J. Agric. Econ. 2011, 93, 407-414. [CrossRef]

24. Kim, Y.; Manley, J.; Radoias, V. Medium and long-term consequences of pollution on labor supply: Evidence from Indonesia. J. Labor Econ. 2017, 6, 5. [CrossRef]

25. Chen, S.; Oliva, P.; Zhang, P. The Effect of Air Pollution on Migration: Evidence from China; NBER Working Paper No. 24036; National Bureau of Economic Research: Cambridge, MA, USA, 2017. [CrossRef]

26. Qin, Y.; Zhu, H. Run Away? Air Pollution and Emigration Interests in China. Popul. Econ. 2018, 31, $235-266$. [CrossRef]

27. Kahn, M.E. Smog Reduction's Impact on California County Growth. J. Reg. Sci. 2000, 40, 565-582. [CrossRef]

28. Akpalu, W.; Ametefee, K.N. Gold Mining Pollution and the Cost of Private Healthcare: The Case of Ghana. Ecol. Econ. 2017, 142, 104-112. [CrossRef]

29. Fu, S.H.; Viard, V.B.; Zhang, P. Air Pollution and Manufacturing Firm Productivity: Nationwide Estimates for China. 2017. Available online: http://www.ckgsb.com/uploads/pollution_and_productivity.pdf (accessed on 19 February 2020).

30. Copeland, B.R.; Taylor, M.S. North-South Trade and the Environment. Q. J. Econ. 1994, 9, 755-787. [CrossRef]

31. Reppelin-Hill, V. Trade and Environment: An Empirical Analysis of the Technology Effect in the Steel Industry. J. Environ. Econ. Manag. 1999, 38, 283-301. [CrossRef]

32. Li, B.; Wu, S. Effects of local and civil environmental regulation on green total factor productivity in China: A spatial Durbin econometric analysis. J. Clean Prod. 2017, 153, 342-353. [CrossRef]

33. Song, T.; Zheng, T.G.; Tong, L.J. An empirical test of the environmental Kuznets curve in China: A panel cointegration approach China. Am. Econ. Rev. 2008, 19, 381-392. [CrossRef]

34. Tientao, A.; Legros, D.; Pichery, M.C. Technology spillover and TFP growth: A spatial Durbin model. J. Int. Econ. 2016, 145, 21-31. [CrossRef]

35. Hering, L.; Poncet, S. Environmental Policy and Exports: Evidence from Chinese Cities. J. Environ. Econ. Manage. 2014, 68, 296-318. [CrossRef]

36. Broner, F.; Bustos, P.; Carvalho, V. Sources of Comparative Advantage in Polluting Industries; NBER Working Paper No. 18337; National Bureau of Economic Research: Cambridge, MA, USA, 2012. [CrossRef]

37. Van, A.D.; Mar Tin, R.V.; Brauer, M. Use of satellite observations for long-term exposure assessment of global concentrations of fine particulate matter. Environ. Health Perspect. 2015, 123, 135-143.

38. Cole, M.A. Trade, the pollution haven hypothesis and the environmental Kuznets curve: Examining the linkages. Ecol. Econ. 2004, 48, 71-81. [CrossRef] 
39. Berman, E.; Bui, L.T. Environmental Regulation and Productivity: Evidence from Oil Refineries. Rev. Econ. Stat. 2001, 83, 498-510. [CrossRef]

40. Shadbegian, R.J.; Gray, W.B. What determines environmental performance at paper mills: The roles of abatement spending, regulation, and efficiency. E J. Econ. Anal. Policy 2003, 3, 1144-1163. [CrossRef]

(C) 2020 by the authors. Licensee MDPI, Basel, Switzerland. This article is an open access article distributed under the terms and conditions of the Creative Commons Attribution (CC BY) license (http://creativecommons.org/licenses/by/4.0/). 